\title{
Divergência genética de Etlingera elatior baseada em caracteristicas agromorfológicas para flores de corte ${ }^{(1)}$
}

\author{
CHARLESTON GONÇALVES(2); CARLOS AUGUSTO COLOMBO(3) \\ e CARLOS EDUARDO FERREIRA DE CASTRO(4)
}

\begin{abstract}
RESUMO
Apesar da grande aceitabilidade do bastão do imperador (Etlingera elatior) pelo consumidor, seu cultivo e mercado ainda são restritos, devido à elevada massa das inflorescências (acima de $1 \mathrm{~kg}$ ), o que dificulta os processos de colheita, manuseio, embalamento e transporte. Objetivou-se neste trabalho a realizar a caracterização agromorfológica e estimar a divergência genética entre acessos de Etlingera elatior (Jack) R.M. Sm. com padrão para flor de corte. Um stand de 75 acessos resultantes do cruzamento ao acaso entre os genótipos da coleção de germoplasma com variabilidade para inflorescências de interesse comercial, mantêm-se em cultivo na Unidade de Pesquisa e Desenvolvimento de Ubatuba. Dezessete descritores foram avaliados relativos a folha, inflorescência e a infrutescência. A massa da inflorescência, comprimento e diâmetro da haste floral, altura e diâmetro da inflorescência foram selecionados como os descritores de maior importância para seleção de acessos com padrão para a comercialização como flor de corte. Foram selecionados 12 acessos promissores, possuindo características adequadas ao mercado e com boa combinação de formas e coloração de brácteas.

Palavras-chave: Bastão do imperador, descritores, coleção de germoplasma, melhoramento, floricultura tropical.
\end{abstract}

\begin{abstract}
Genetic divergence of Etlingera elatior based on agro-morphological features for cut flowers Despite the wide acceptability Torch Ginger (Etlingera elatior) by the consumer market and its cultivation are still restricted due to the high mass of inflorescences (over $1 \mathrm{~kg}$ ), which complicates the process of harvesting, handling, packaging and transportation. The objective of this work was to characterize agromorphological and estimate the genetic divergence among Etlingera elatior ( Jack) R.M. Sm. with standard cut flower. A stand of 75 genotypes resulting from crosses between genotypes at random from the collection of germplasm with variability inflorescences of commercial interest, they keep on growing in the Research and Development of Ubatuba. Seventeen descriptors were evaluated on the leaf, inflorescence and infrutescence. The inflorescence mass, length and diameter of the flowering stem, height and flower diameter were selected as the most important descriptors for selecting accessions with standard marketing as cut flower. We selected 12 promising accessions, with characteristics appropriate to the market and with good combination of shapes and coloring bracts.

Keywords: Torch ginger; descriptors, germplasm collection, improvement, tropical floriculture.
\end{abstract}

\section{INTRODUCÃO}

O setor de floricultura e plantas ornamentais teve uma notável taxa de crescimento de $10 \%$ nas últimas décadas, contrariando as expectativas do setor devido à crise econômica mundial, esse fato se deve ao fortalecimento e estruturação comercial do mercado interno, que absorveu 95\% do valor da comercialização do setor (CASTRO, 2010). O mesmo autor relata que o perfil da floricultura praticada no Brasil está evoluindo, com produtos tradicionais (rosa, crisântemo, etc) compartilhando o mercado com flores e folhagens de origem tropical, e parte dessa evolução pode ser atribuída à demanda mundial por novos produtos e à organização das bases produtivas no Brasil e em outros países da América Latina, com destaque para a Costa Rica, que impulsionaram sua oferta no mercado internacional. Castro (2010) relata ainda que, quanto à demanda por novidades, as flores e folhagens tropicais, pela diversidade de formas, cores e uso, passaram a atender prontamente à necessidade existente.
O mercado brasileiro de flores e plantas ornamentais é crescente e vigoroso, exibindo, ao longo dos últimos anos, taxas de crescimento da ordem de $9,0 \%$ a $10,0 \%$ ao ano em valor e de $8,0 \%$ a $12,0 \%$ nas quantidades movimentadas (SEBRAE, 2010).

Segundo Vencato et al., (2006), a capacidade de geração de ocupação e renda da floricultura é muito grande, empregando aproximadamente 120 mil pessoas, sendo que $80 \%$ da mão de obra é formada por mulheres, além de $18,7 \%$ do total ser de origem familiar. $\mathrm{O}$ mesmo autor relata ainda que, entre as culturas agrícolas, a floricultura destaca-se por empregar, em média, de 10 a 15 funcionários por hectare, superando em dez vezes os demais cultivos.

O bastão do imperador (Etlingera elatior) é uma planta perene, exuberante por seu porte e formas exóticas de suas inflorescências, sendo muito apreciado para uso em paisagismo ou para produção de flores cortadas destinadas aos arranjos florais pela beleza e valor ornamental que apresenta (RIBEIRO et. al, 2012). O mesmo autor descreve o bas-

\footnotetext{
(1) Recebido para publicação em 11/03/2013 e aceito em 22/03/2014;

(2)Pesquisador Científico Instituto Agronômico (IAC) Centro de Horticultura - charleston@iac.sp.gov.br;

${ }^{(3)}$ Pesquisador Científico Instituto Agronômico (IAC) Centro de Recursos Genéticos Vegetais - ccolombo@iac.sp.gov.br;

(3)Pesquisador Científico Instituto Agronômico (IAC) Centro de Horticultura - ccastro@iac.sp.gov.br
} 
tão do imperador sendo uma planta herbácea, rizomatosa, entouceirante, de 2 a $4 \mathrm{~m}$ de altura que tem sido cultivada como flor de corte, mas é explorada também no paisagismo. Segundo Terao et al. (2005), no mercado internacional essas flores são consideradas muito apreciadas, entretanto, para a espécie, não são disponibilizadas informações sobre padrões de produção, nem recomendações de adubação seguras.

Um dos fatores que impedem a expansão da comercialização de inflorescências do bastão do imperador refere-se ao elevado peso das inflorescências. No Brasil, as regiões produtoras de inflorescências de bastão do imperador normalmente estão em locais distantes dos principais centros consumidores, representados pelos Estados do Sudeste e Sul do país. Devido à perecibilidade da inflorescência, após a colheita é requerido o transporte aéreo para assegurar a rapidez da comercialização do produto. A baixa disponibilidade de espaços nos compartimentos dos aviões, a falta de regularidade dos vôos e os custos elevados desse transporte são fatores preponderantes que retardam a expansão do mercado de inflorescências cortadas de bastão do imperador.

Objetivou-se neste trabalho realizar a caracterização agromorfológica e estimar a divergência genética entre acessos de Etlingera elatior com padrão para flor de corte.

\section{MATERIAL E MÉTODOS}

Setenta e cinco acessos da Coleção de Germoplasma de Zingiberales Ornamentais do Instituto Agronômico (CGZO-IAC), todos provindos de cruzamento ao acaso, contrastantes quanto às características de cor, tamanho e altura da inflorescência, foram avaliados em um experimento conduzido na Unidade de Pesquisa e Desenvolvimento de Ubatuba, Estado de São Paulo, com latitude 2326'02” S, longitude $45^{\circ} 04^{\prime} 16^{\prime \prime} \mathrm{W}$, pluviosidade média anual de 2.700 $\mathrm{mm}$ e a 8 metros acima do nível do mar, durante os anos de 2009 e 2010.

O delineamento foi inteiramente casualizado, com seis repetições, as mudas de aproximadamente $20 \mathrm{~cm}$ provindas de sementes foram plantadas num espaçamento de $3 \times 3 \mathrm{~m}$, em abril de 2005 e avaliados em 2009 e 2010. Para a caracterização agromorfológica, foram utilizados descritores para Folha: Comprimento foliar (CFO), da base ao ápice do limbo foliar, selecionando a folha mais alta; Largura do limbo foliar (LLF), a medida foi realizada na parte mediana da folha; Comprimento do pecíolo foliar (CPF), da base até o primeiro folíolo, e Número de folíolos (NFO). Inflorescência: Comprimento da haste floral $(\mathrm{CHF})$, medido da base até o início da inflorescência; Diâmetro da haste floral (DHF), medido a $70 \mathrm{~cm}$ da inflorescência; Coloração da haste floral (COH); Altura da inflorescência (AIN), medido do ápice da inflorescência até o início do pedúnculo floral; Diâmetro da inflorescência (DIN); Coloração das brácteas (COB), medido através de colorímetro; Formato da inflorescência (FIN); Presença de folhas nas brácteas (PFB); Projeção do miolo na inflorescência (PMI); Massa fresca da inflorescência (MFI), medida em balança de precisão da base ao topo da inflorescência, e Massa fresca comercial da inflorescência (MFC), medida com comprimento da haste floral padronizada em 80 centímetros. Infrutescência:
Diâmetro longitudinal da infrutescência (DLI); Diâmetro transversal da infrutescência (DTI).

O critério de agrupamento de médias de Scott \& Knott (SCOTT; KNOTT, 1974) a 5\% de probabilidade foi utilizado para os descritores agromorfológicos avaliados. Os dados agromorfológicos foram analisados por meio de análise de componentes principais. Esta análise permite diferenciar e agrupar o material do estudo a partir de identidades reveladas pelo conjunto de dados agromorfológicos obtidos.

A divergência genética entre os acessos foi obtida através da distância Euclidiana, mediante a padronização dos dados, devido às diferentes escalas de mensuração.

Para seleção dos genótipos promissores foram selecionados cinco descritores com maior relação em massa e tamanho das inflorescências, sendo eles massa fresca padronizada (MFC), para este descritor a seleção foi realizada com as inflorescências que apresentaram as menores massas, na faixa de 166,25 a 235,07 g, visando à redução de custo em transporte e embalagem; comprimento da haste floral (CHF), foram selecionados os acessos que ficaram com os valores médios entre 100,58 a $127,58 \mathrm{~cm}$; diâmetro da haste floral (DHF), os acessos selecionados foram aqueles que obtiveram valores médios entre 1,30 a 1,65 cm; diâmetro da inflorescência (DIN), os melhores valores selecionados para flores de corte para esse descritor foram os valores entre 14,08 a $16,25 \mathrm{~cm}$ e altura da inflorescência, (AIN), sendo selecionados os acessos com os valores médios entre 12,63 a 14,68 $\mathrm{cm}$. A escolha dos acessos foi obtida através de uma escala de pontos, cada vez que o acesso ficava na faixa selecionada como ótima recebiam uma pontuação, aqueles que obtiveram a maior pontuação foram considerados os acessos com características superiores.

As análises estatísticas foram realizadas utilizando os programas computacionais STATISTICA (STATSOFT, 1999) e GENES (CRUZ, 2001).

\section{RESULTADOS E DISCUSSÃO}

Observou-se variabilidade para os todos os descritores avaliados, os valores e classes estatísticas são apresentados no anexo 1. Para os descritores de folha, a característica comprimento foliar (CFO) foi a mais diversificada, tendo valores de 6,41 a 4,08 metros, com oito classes de médias e $\mathrm{CV} \%=4,54$. Para largura do limbo foliar (LLF), os valores ficaram entre 156,17 a 96,25 centímetros, sendo obtidas cinco classes de médias e $\mathrm{CV} \%=7,71$. Os descritores comprimento do pecíolo foliar (CPF) com valores entre 159,00 a 79,33 e número de folíolos (NFO) com valores entre 33,42 a 19,08, ambos descritores, apresentaram quatro classes de médias com CV\% $=12,24$ e 11,92, respectivamente. Para os descritores de inflorescência, a característica comprimento da haste floral (CHF) com valores entre 172,58 a 87,00 centímetros, apresentou seis classes de média, com $\mathrm{CV} \%=9,64$. Para o descritor diâmetro da haste floral (DHF), os acessos apresentaram valores entre 1,88 a 1,09 centímetros e quatro classes de médias, com $\mathrm{CV} \%=$ 10,63. Para o descritor alturas da inflorescência (AIN), os valores foram de 16,50 a 10,58 centímetros, apresentando seis classes de médias, com $\mathrm{CV} \%=6,65$. Para o descritor 
diâmetro da inflorescência (DIN), os acessos tiveram valores entre 21,04 a 12,58 centímetros, com cinco classes de média e $\mathrm{CV} \%=8,88$. A massa fresca da inflorescência (MFI) e a massa fresca da inflorescência padronizada (MFC) tiveram seus valores entre 581,62 a 213,21 gramas e 480,93 a 166,25 gramas, respectivamente. Ambas apresentaram cinco classes de médias, com CV\% $=15,08$ e 16,10, respectivamente. Os descritores de infrutescência diâmetro longitudinal (DLI) e diâmetro transversal (DTI) tiveram seus valores entre 20,46 a 7,29 e 14,21 a 6,50, respectivamente. Para DLI foram observadas sete classes de médias e para DTI seis classes, os CV\% foram 9,25 e 8,55, respectivamente.

As inflorescências avaliadas apresentaram diferenças no formato, sendo 35 acessos com inflorescências globosa e 40 com lanceolada (Figura 1 e Anexo 1).
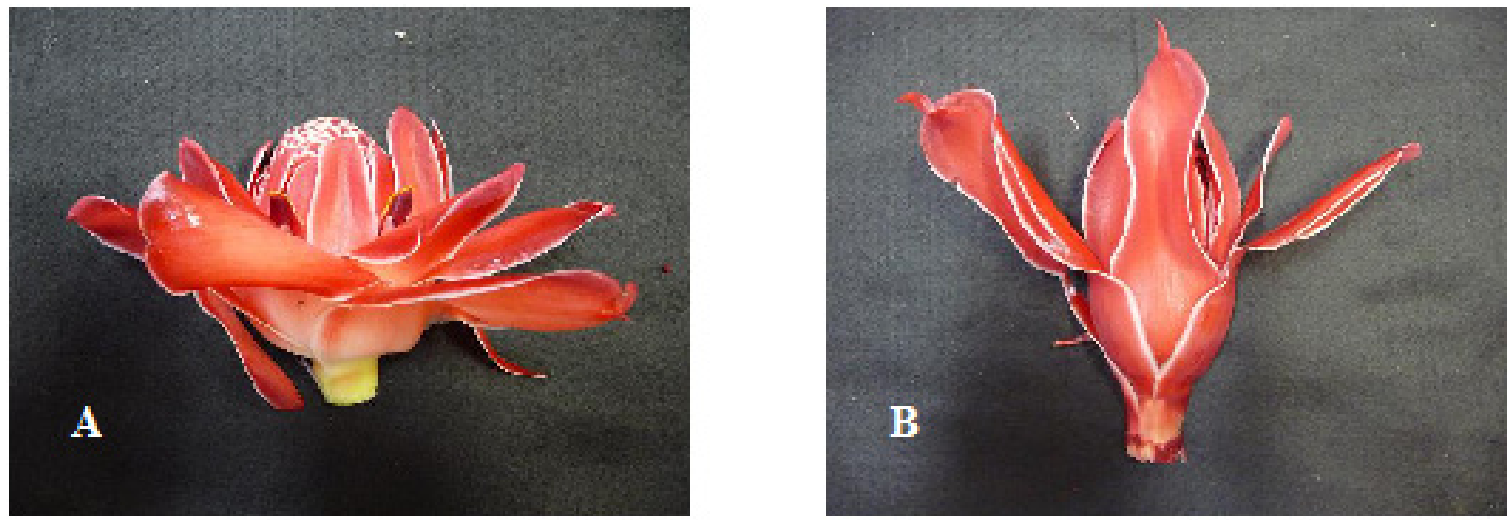

Figura 1. Formato da inflorescência de bastão do imperador. A: Globoso. B: lanceolado. Figure 1. Shape inflorescence of Torch ginger. A: Globose. B: Lanceolate.

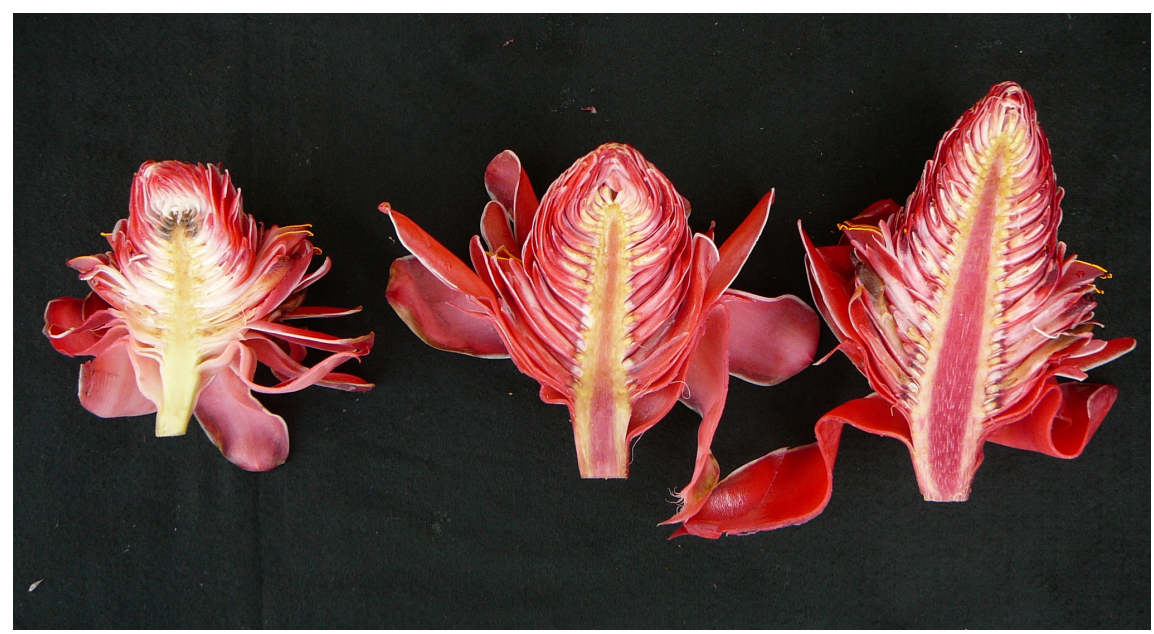

Figura 2. Projeção do miolo das inflorescências. A: Pouco projetado. B: Projeção mediana. C: Muito projetado. Figure 2. Center projection of the inflorescences A: Less projection. B: Moderate projection. C: Higher projection.

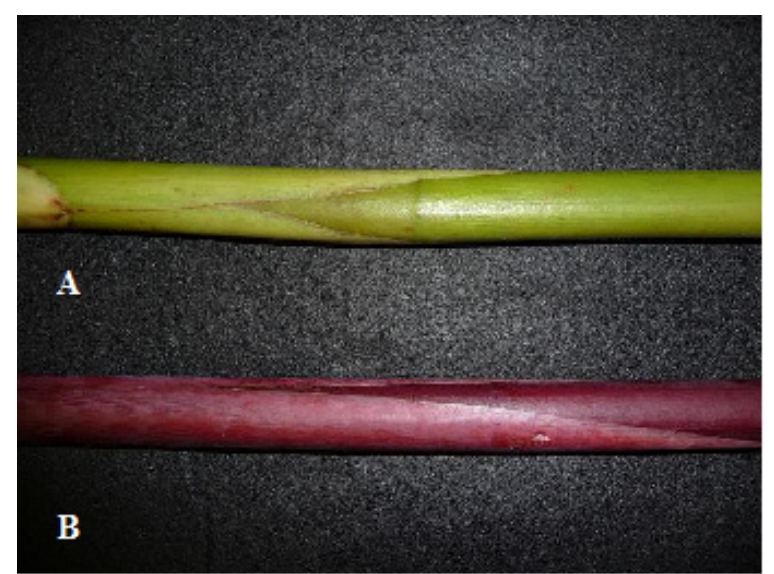

Figura 3. Coloração das hastes florais de bastão do imperador. A: cor verde. B: cor vinho.

Figure 3. Color of floral stems of Torch ginger. A: green. B: purple. 
Quanto à projeção do miolo da inflorescência, foram encontrados na coleção 11 acessos com miolo pouco projetado, 53 acessos com projeção mediana e 11 acessos com miolo da inflorescência muito projetado (Figura 2).

$\mathrm{Na}$ avaliação feita para a coloração da haste floral, os acessos da coleção apresentaram duas colorações para has- te floral, sendo: 33 acessos com coloração da haste floral verde e 42 acessos com coloração vinho (Figura 3 ).

$\mathrm{Na}$ avaliação feita para a coloração das brácteas, pode-se notar a ocorrência de quatro colorações distintas, vermelho escuro, vermelho médio, rosa médio e rosa claro (Figura 4).

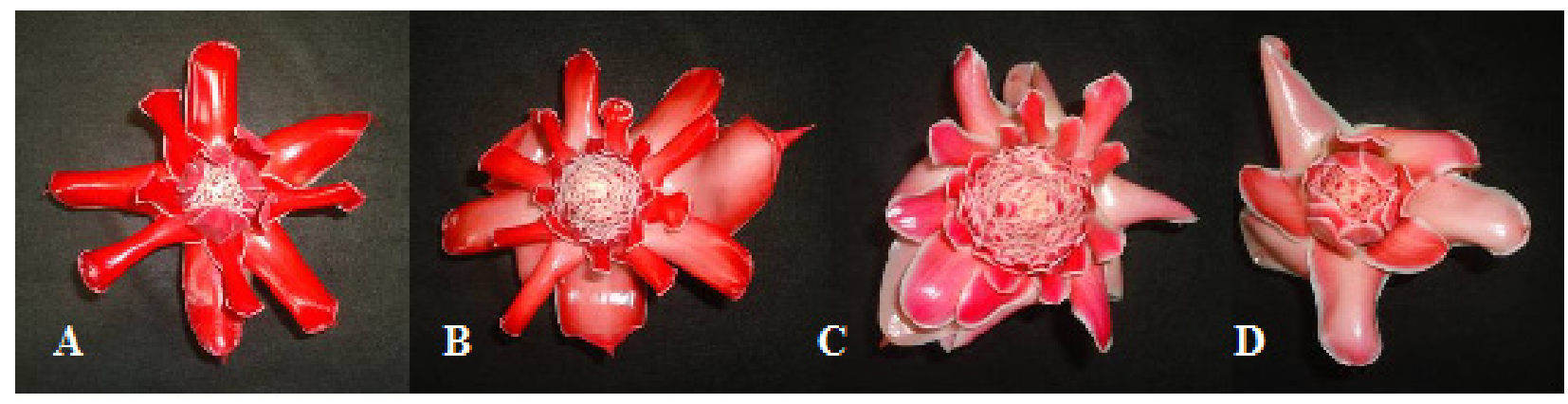

Figura 4. Cores das brácteas das inflorescências de E. elatior. A: vermelho escuro. B: vermelho médio. $\mathrm{C}$ : rosa médio. D: rosa claro.

Figure 4. Colors of E. elatior inflorescence bracts. A: dark red. B: medium red. C: medium pink. D: light pink.

A divergência genética entre os genótipos foi obtida através da distância Euclidiana, mediante a padronização dos dados, devido às diferentes escalas de mensuração. Na análise dos 75 genótipos pelo dendrograma foi possível observar a formação de quatro grupos distintos, obtidos pelo método UPGMA (Unweighted Pair Group Method with Arithmetic Mean) (Figura 5).

O primeiro grupo foi formado pelos acessos 2, 4, 6, 14, $16,18,22,29,30,32,34,38,41,42,46,48,50,54,55$, $57,58,61,65,66,70,73$ e 74 . As médias do grupo foram maiores para as seguintes características agromorfológicas: diâmetro longitudinal e transversal da infrutescência, apresentando vários subgrupos.

O segundo grupo foi formado pelos acessos 20, 24, 26, $36,45,49,62$ e 69 , e houve também uma separação por subgrupos onde a maior dissimilaridade entre o grupo ficou por conta dos acessos 24 e 45 . O grupo apresentou as maiores médias para os descritores comprimento foliar, número de folíolos e comprimento da haste floral, e as menores médias para os descritores altura da inflorescência e diâmetro da inflorescência e massa fresca comercial.
O terceiro grupo foi formado pelos acessos 8, 10, 12, $13,17,21,25,28,47$ e 53, apresentando cinco subgrupos. Para este grupo, as médias dos descritores apresentaram maiores valores para largura foliar, comprimento do pecíolo foliar e menores valores médios para os descritores: comprimento foliar, comprimento da haste floral, diâmetro da haste floral, massa fresca total da inflorescência, diâmetros longitudinal e transversal da infrutescência.

O quarto grupo foi formado por 30 acessos, apresentando oito subgrupos, alguns subgrupos com muita dissimilaridade. O grupo apresentou para a maioria dos acessos maiores valores médios para os seguintes descritores avaliados: diâmetro da haste floral, altura da inflorescência, diâmetro da inflorescência, massa fresca e massa fresca padronizada da inflorescência e menores valores para as características largura foliar, comprimento do pecíolo foliar e numero de folíolos.

A similaridade genética entre os materiais avaliados pode ser explicada pela origem dos mesmos, uma vez que estes descendem de uma mesma mãe. 


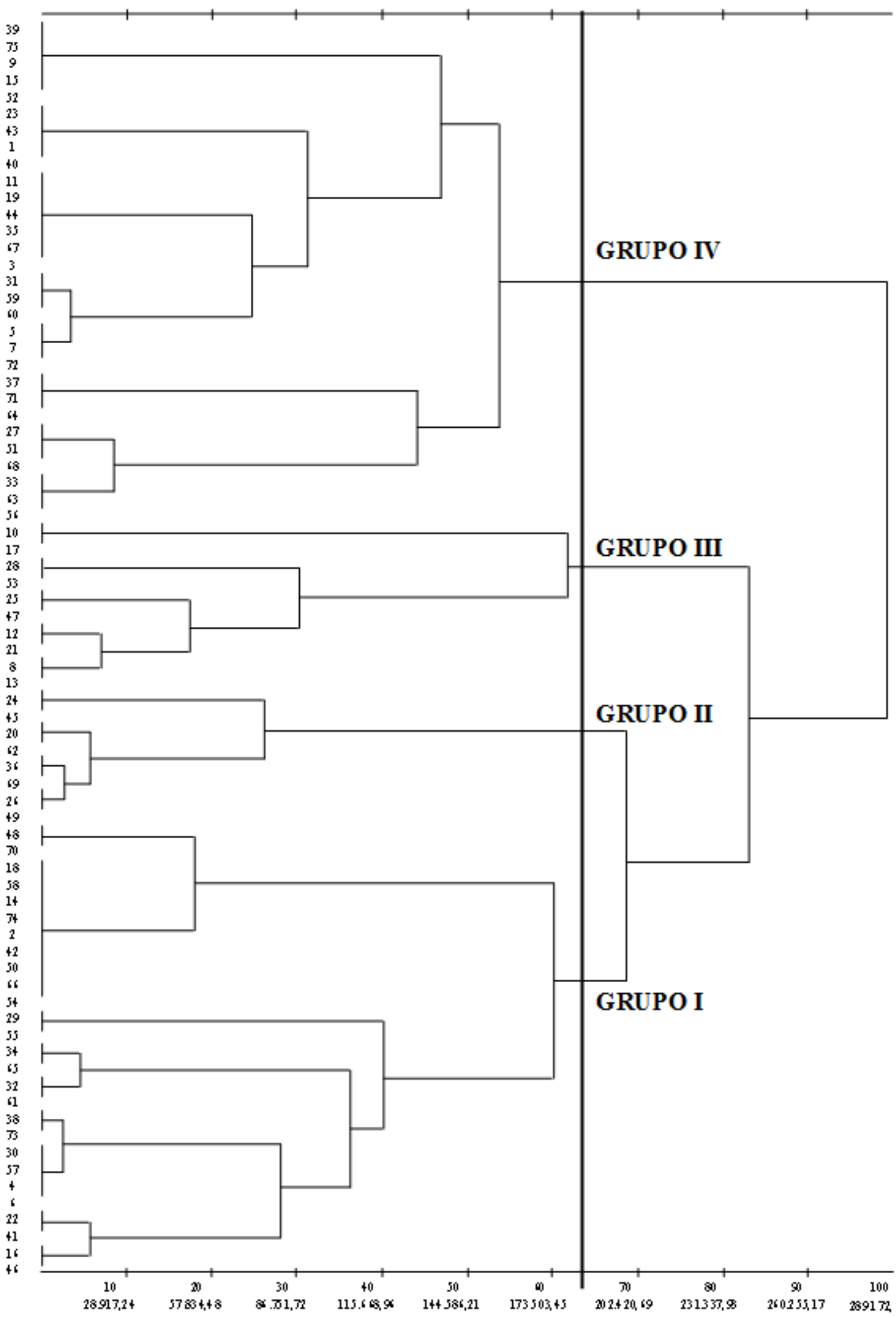

Figura 5. Análise de divergência genética para 75 genótipos de Etlingera elatior. As distâncias genéticas foram obtidas com base em 13 variáveis agromorfológicos e quantificadas através da distância Euclidiana padronizada e o agrupamento foi feito pelo método UPGMA.

Figure 5. Analysis of genetic diversity for 75 genotypes E. elatior. Genetic distance were obtained based on 13 agromorphological variables and quantified by standardized Euclidean distance and clustering was done by UPGMA. 
Com o auxílio da análise de componentes principais, visualizou-se, em um gráfico bidimensional devido ao acúmulo de $71 \%$ nos dois primeiros componentes principais, que a distribuição e formação de grupos de acessos foram similares aos apresentados pela análise do dendrograma do UPGMA (Figura 6).

O valor absorvido por cada componente foi 58,4\% e 12,6\%, respectivamente para a Componente Principal 1 e Componente Principal 2. As duas componentes absorveram juntas $71,0 \%$ da variação observada dos dados. Desse modo, as duas componentes explicam grande parte da variação observada na análise dos caracteres fenotípicos. Sem dúvidas a componente principal 1 foi considerada a mais importante, pois sozinha explica 58,4 \% de toda a variação.

Em conformidade com os índices dos autovalores associados, foi possível verificar quais dos 13 descritores avaliados apresentaram maior contribuição para cada uma das componentes. Para a primeira componente, dentre os descritores que mais influenciaram na distribuição dos acessos avaliados destacam-se diâmetro da inflorescência, massa fresca total da inflorescência e massa fresca comercial da inflorescência com autovetores de 0,3628; 0,4225 e 0,4015 , respectivamente. Para o segundo componente, os descritores que mais influenciaram foram número de folíolos, diâmetro transversal da infrutescência e diâmetro da haste floral com autovetores de 0,4007; 0,3708 e 0,3793, respectivamente.

Os grupos formados a esquerda do eixo das abscissas apresentaram menores valores para diâmetro, massa total e comercial da inflorescência, descritores considerados importantes para seleção dos acessos menores e de menor massa, contrastando com os acessos que ficaram a direita do eixo das abscissas, apresentando os maiores valores para os mesmos descritores (Figura 6).

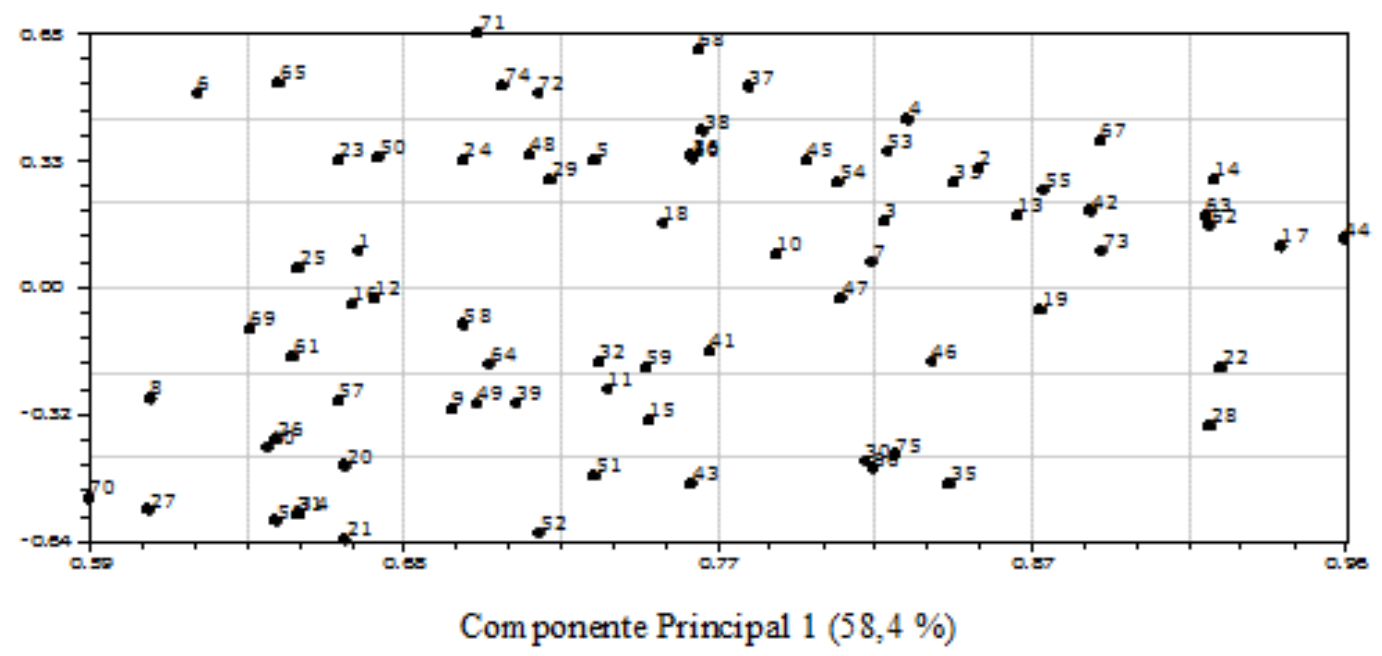

Figura 6. Análise de componentes principais (ACP1 e ACP2) com 75 genótipos de Etlingera elatior baseada em 13 descritores.

Figure 6. Principal components analysis (PCA1 and PCA2) with 75 genotypes E. elatior based on 13 descriptors.

Para a seleção dos acessos visando flores de corte foram elencados cinco descritores: comprimento e diâmetro da haste floral, altura, diâmetro e massa fresca comercial das inflorescências; que indicam os melhores descritores para flores de corte, considerando que a seleção na coleção de germoplasma objetiva a obtenção de plantas com inflorescências menores e de menores massas, ocasionando no menor custo em transporte e embalagem para o produtor.

Os 75 acessos constituintes na coleção de germoplasma foram avaliados para estes cinco descritores, onde os acessos que permaneceram entre as faixas de médias escolhidas para os cinco descritores pontuavam e assim se sobressaiam como os superiores.

Para o comprimento da haste floral, os dados obtidos na análise estatística separaram os 75 acessos em seis classes de média, os valores variaram em média de 87,00 a 172,58 $\mathrm{cm}$. Os acessos selecionados que estavam entre os valores determinados com ótimo foram: 1, 8, 13, 19, 21, 22, 26, 29, $36,39,40,41,42,48,53,54,55,57,58,60,62,63,64,69$, 70, 71, 72 e 75 .

Para o descritor diâmetro da haste floral, os dados foram separados estatisticamente em quatro classes de médias, os valores variaram em média de 1,88 a 1,09 cm. Os acessos selecionados que ficaram dentro da faixa ótima foram: 1, 2, $3,5,7,10,11,12,14,16,17,18,20,21,22,23,24,25,26$, $30,31,32,33,36,37,38,39,41,42,45,46,47,48,49,50$, $51,52,53,54,56,57,60,61,62,63,65,68,69,73,74$ e 75.

Para o descritor altura da inflorescência, os dados agrupados estatisticamente foram separados em seis classes de médias e variaram entre 10,58 a $16,50 \mathrm{~cm}$. Os acessos selecionados foram: $2,4,5,6,7,8,9,10,11,12,14,15,16,17$, $18,19,20,21,22,23,25,27,28,29,32,35,36,37,38,39$, $41,42,45,47,48,49,51,52,53,54,56,57,58,60,61,63$, $65,66,67,71,72,74$ e 75 . 
Os dados do descritor diâmetro da inflorescência foram submetidos à análise estatística e separou as médias em cinco classes que se diferenciaram estatisticamente, perfazendo a faixa de valores de 12,58 a 21,04 cm. Os acessos com valores selecionados para esta característica como as mais promissoras para flores de corte foram 2, 8, 11, 12, 13, $18,19,20,22,26,33,35,36,37,47,48,49,53,55,56,58$, $60,62,65,68$ e 72 .

Os dados de massa fresca padronizada da inflorescência passaram pela análise estatística e foram obtidas cinco classes de médias que ficaram entre os valores de 166,25 a 480,93 g. Essa classe agrupou 20 acessos dentro da faixa selecionada como ótima, sendo eles $1,3,8,12,13,16,19$, $21,26,27,34,36,53,56,58,59,60,62,70$ e 72 .

A escolha dos genótipos foi obtida através de uma escala de pontos, cada vez que o acesso parecia em um dos cinco descritores selecionados acima, eles recebiam uma pontuação. Na tabela 1, pode-se observar a pontuação dos genótipos, sendo aqueles que obtiveram a maior pontuação os genótipos com características superiores.

Tabela 1. Notas dos melhores genótipos entre os descritores selecionados.

Table 1. Score of the best genotypes among the selected descriptors.

\begin{tabular}{|c|c|c|c|c|c|c|c|c|c|c|c|c|c|}
\hline Genótipos & Nota & Genótipos & Nota & Genótipos & Nota & Genótipos & Nota & Genótipos & Nota & Genótipos & Nota & Genótipos & Nota \\
\hline 36 & 5 & 58 & 4 & 39 & 3 & 7 & 2 & 38 & 2 & 74 & 2 & 46 & 1 \\
\hline 53 & 5 & 62 & 4 & 41 & 3 & 10 & 2 & 45 & 2 & 4 & 1 & 50 & 1 \\
\hline 60 & 5 & 72 & 4 & $42 w$ & 3 & 14 & 2 & 47 & 2 & 6 & 1 & 59 & 1 \\
\hline 8 & 4 & 1 & 3 & 49 & 3 & 17 & 2 & 51 & 2 & 9 & 1 & 64 & 1 \\
\hline 12 & 4 & 2 & 3 & 53 & 3 & 23 & 2 & 52 & 2 & 15 & 1 & 66 & 1 \\
\hline 19 & 4 & 11 & 3 & 57 & 3 & 25 & 2 & 55 & 2 & 24 & 1 & 67 & 1 \\
\hline 21 & 4 & 13 & 3 & 63 & 3 & 27 & 2 & 61 & 2 & 28 & 1 & 73 & 1 \\
\hline 22 & 4 & 16 & 3 & 65 & 3 & 29 & 2 & 68 & 2 & 30 & 1 & & \\
\hline 26 & 4 & 18 & 3 & 75 & 3 & 32 & 2 & 69 & 2 & 31 & 1 & & \\
\hline 48 & 4 & 20 & 3 & 3 & 2 & 33 & 2 & 70 & 2 & 34 & 1 & & \\
\hline 56 & 4 & 37 & 3 & 5 & 2 & 35 & 2 & 71 & 2 & 40 & 1 & & \\
\hline
\end{tabular}

Os acessos 36, 53 e 60 que tiveram nota cinco foram aqueles que se destacaram entre os cinco descritores selecionados, sendo eleitos como superiores. Os acessos que tiveram nota quatro também são promissores com exceção dos acessos 22 e 48 que não pontuaram do descritor considerado mais importante (massa fresca comercial).

Os descritores dos acessos selecionados são apresentas na tabela 2 .

Tabela 2. Características dos genótipos selecionados como adequadas para flor de corte.

Table 2. Characteristics of genotypes selected as suitable for cut flower.

\begin{tabular}{|c|c|c|c|c|c|c|c|c|c|c|c|c|c|c|c|c|c|}
\hline Genótipos & CFO & LLF & CPF & NFO & $\mathrm{CHF}$ & DHF & AIN & DIN & MFT & MFC & DLI & DTI & $\mathrm{COH}$ & FIN & СОВ & PMI & PFB \\
\hline 36 & 593,50 & 121,75 & 115,83 & 33,33 & 114,33 & 1,65 & 13,88 & 16,13 & 311,68 & 233,82 & 10,46 & 8,79 & verde & Globoso & VE & Média & Não \\
\hline 53 & 463,75 & 120,00 & 132,17 & 29,58 & 103,08 & 1,30 & 12,75 & 14,08 & 262,45 & 194,87 & 10,63 & 9,04 & vinho & Lanceolado & VM & Média & Não \\
\hline 60 & 486,08 & 114,92 & 114,08 & 28,58 & 121,92 & 1,37 & 12,67 & 14,88 & 288,73 & 205,92 & 9,17 & 8,25 & verde & Lanceolado & RM & Média & Não \\
\hline 8 & 477,92 & 115,83 & 138,25 & 27,08 & 106,17 & 1,12 & 13,24 & 14,77 & 213,21 & 174,11 & 11,33 & 9,75 & vinho & Lanceolado & VM & Média & Não \\
\hline 12 & 502,50 & 119,33 & 121,92 & 30,17 & 129,67 & 1,30 & 13,29 & 16,25 & 321,31 & 223,21 & 7,75 & 6,96 & vinho & Lanceolado & VE & Média & Não \\
\hline 19 & 484,08 & 137,08 & 128,17 & 20,42 & 104,33 & 1,21 & 12,68 & 14,58 & 277,70 & 215,56 & 11,13 & 9,38 & verde & Lanceolado & $\mathrm{RC}$ & Pouca & Não \\
\hline 21 & 474,42 & 132,33 & 95,25 & 24,58 & 125,58 & 1,44 & 13,93 & 16,75 & 321,97 & 226,58 & 8,25 & 7,42 & vinho & Globoso & VE & Média & Não \\
\hline 26 & 575,08 & 141,92 & 159,00 & 24,75 & 125,17 & 1,53 & 12,04 & 16,13 & 270,51 & 178,40 & 11,17 & 8,83 & vinho & Lanceolado & VE & Pouca & Não \\
\hline 56 & 477,92 & 136,67 & 98,17 & 29,67 & 87,00 & 1,39 & 13,13 & 15,92 & 277,40 & 226,09 & 11,29 & 9,88 & verde & Lanceolado & $\mathrm{RC}$ & Média & Não \\
\hline 58 & 447,33 & 115,50 & 84,33 & 28,08 & 114,58 & 1,26 & 12,79 & 14,46 & 271,00 & 204,20 & 11,46 & 8,71 & vinho & Lanceolado & $\mathrm{RC}$ & Média & Não \\
\hline 62 & 469,25 & 125,58 & 90,67 & 27,08 & 119,25 & 1,33 & 11,71 & 14,08 & 265,56 & 200,27 & 10,29 & 8,88 & verde & Lanceolado & VE & Pouca & Não \\
\hline 72 & 484,83 & 119,33 & 93,92 & 26,42 & 117,33 & 1,28 & 13,08 & 16,04 & 303,63 & 230,41 & 10,38 & 8,58 & verde & Lanceolado & VM & Média & Não \\
\hline
\end{tabular}

CFO: comprimento foliar; LLF: largura foliar; CPF: comprimento do pecíolo foliar; NFO: número de folíolos;

CHF: comprimento da haste floral; DHF: diâmetro da haste floral; AIN: altura da inflorescência; DIN: diâmetro da inflorescência; MFT: massa fresca da inflorescência; MFC: massa fresca comercial da inflorescência; DLI: diâmetro longitudinal da infrutescência; DTI: diâmetro transversal da infrutescência; $\mathrm{COH}$ : cor da haste floral; FIN: formato da inflorescência; COB: cor das brácteas (VE: vermelho escuro; VM: vermelho médio; RC: rosa claro; RM: rosa médio); PMI: projeção do miolo da inflorescência; PFB: presença de folha nas brácteas. 


\section{CONCLUSÃO}

A Coleção de Germoplasma de Etlingera elatior do Instituto Agronômico (IAC) apresenta importante diversidade genética e as características comprimento foliar, diâmetro longitudinal da infrutescência, comprimento da haste floral e altura da inflorescência apresentaram os maiores índices de variabilidade.

Foi possível selecionar os genótipos 8, 12, 19, 21, 26, $36,53,56,58,60,62$ e 72 como promissores para flor de corte, destacando três genótipos 36,53 e 60 .

Foi possível propor descritores morfológicos para corte de Etlingera elatior.

Com a caracterização da Coleção de Germoplasma de Etlingera elatior do Instituto Agronômico - IAC cria-se um histórico de comportamento das plantas contidas na coleção no sentido de direcionar os trabalhos de melhoramento genético e seleção de plantas com características desejadas.

\section{REFERÊNCIAS}

CASTRO, C. E. F. Zingiberales ornamentais diversificando a floricultura tropical. Horticultura Brasileira. v. 28, n. 1, contra capa, 2010.
CRUZ, C. D. Programa GENES: versão Windows: aplicativo computacional em genética e estatística. Viçosa: UFV, 2001, 648p.

RIBEIRO, T.R.; ALMEIDA, E.F.A; FRAZÃO, J.E.M; CARVALHO, J.G. Bastão do Imperador. In: PAIVA, P.D.O; ALMEIDA, E.F.A. Produção de flores de corte. Lavras: UFLA, 2012. v. 1, p. 90-103, 2012.

SEBRAE. Série Manuais Téenicos Institucionais para a Produção e Comercialização de Folhas e Folhagens Tropicais de Corte. v. 1, 2010, 141p.

SCOTT, A. J.; KNOTT, M. A. A cluster analysis method for grouping means in the analysis of variance. Biometrics, v. 30, n. 3, p. 507-512, 1974.

TERAO, D.; CARVALHO, A.C.P.P.; BARROSO, T.C.S. Flores Tropicais. Brasília: Embrapa Informações Tecnológicas, 2005, 225p.

VENCATO, A. Anuário brasileiro das flores 2006. Santa Cruz do Sul: Gazeta Santa Cruz, 2006, 112 p.

Anexo 1. Valores médios referentes aos descritores agromorfológicos avaliados em 75 acessos de E. elatior da Coleção de Germoplasma do Instituto agronômico - IAC.

Annex 1. Average values for the agromorphological descriptors evaluated in 75 accessions of E. elatior Germplasm Collection Agronomic Institute - IAC.

\begin{tabular}{|c|c|c|c|c|c|c|c|c|c|c|c|c|c|c|c|c|c|}
\hline Genótipos & COF & LLF & CPF & NFO & $\mathrm{CHF}$ & DHF & AIN & DIA & MFI & MFC & DLI & DTI & $\mathrm{COH}$ & FIN & СОВ & PMI & PFB \\
\hline 1 & 429,75 & 114,92 & 151,75 & 24,42 & 106,25 & 1,43 & 11,17 & 13,42 & 311,81 & 235,07 & 10,96 & 8,79 & verde & Lanceolado & VE & Pouca & Não \\
\hline 2 & 459,67 & 133,58 & 111,42 & 23,33 & 137,67 & 1,58 & 13,04 & 14,79 & 429,75 & 333,25 & 11,50 & 9,21 & verde & Lanceolado & VM & Média & Não \\
\hline 3 & 445,00 & 118,42 & 96,17 & 22,00 & 139,00 & 1,37 & 16,04 & 17,23 & 342,65 & 231,52 & 7,71 & 6,50 & verde & Globoso & RM & Muita & Não \\
\hline 4 & 516,58 & 137,08 & 114,83 & 23,50 & 154,83 & 1,69 & 14,25 & 19,29 & 494,50 & 377,05 & 10,46 & 8,79 & verde & Globoso & VE & Média & Não \\
\hline 5 & 479,00 & 118,67 & 114,67 & 26,25 & 155,50 & 1,55 & 13,50 & 18,50 & 560,90 & 448,09 & 10,42 & 9,33 & verde & Lanceolado & VE & Média & Não \\
\hline 6 & 489,08 & 114,67 & 92,08 & 24,42 & 172,58 & 1,83 & 14,21 & 19,58 & 581,62 & 480,93 & 11,13 & 9,63 & verde & Globoso & VM & Média & Não \\
\hline 7 & 465,42 & 110,67 & 90,08 & 19,33 & 135,67 & 1,36 & 14,00 & 18,08 & 423,94 & 322,85 & 9,46 & 8,29 & vinho & Globoso & VE & Média & Não \\
\hline 8 & 477,92 & 115,83 & 138,25 & 27,08 & 106,17 & 1,12 & 13,24 & 14,77 & 213,21 & 174,11 & 11,33 & 9,75 & vinho & Lanceolado & VM & Média & Não \\
\hline 9 & 504,00 & 118,75 & 97,58 & 25,58 & 144,50 & 1,79 & 14,00 & 18,58 & 432,58 & 309,11 & 13,17 & 11,42 & verde & Globoso & VM & Média & Não \\
\hline 10 & 531,17 & 126,83 & 112,00 & 26,17 & 143,83 & 1,58 & 14,29 & 19,46 & 466,92 & 338,66 & 9,38 & 8,54 & vinho & Globoso & $\mathrm{RM}$ & Média & Não \\
\hline 11 & 500,67 & 115,83 & 118,83 & 28,42 & 133,50 & 1,41 & 12,63 & 16,17 & 340,23 & 267,25 & 8,46 & 7,29 & vinho & Lanceolado & VM & Média & Não \\
\hline 12 & 502,50 & 119,33 & 121,92 & 30,17 & 129,67 & 1,30 & 13,29 & 16,25 & 321,31 & 223,21 & 7,75 & 6,96 & vinho & Lanceolado & VE & Média & Não \\
\hline 13 & 499,17 & 118,33 & 136,00 & 24,50 & 119,00 & 1,22 & 12,42 & 14,88 & 221,15 & 166,25 & 10,00 & 9,04 & vinho & Lanceolado & VE & Pouca & Não \\
\hline 14 & 506,75 & 120,25 & 149,92 & 28,92 & 140,42 & 1,55 & 13,33 & 16,92 & 366,38 & 264,73 & 9,21 & 8,42 & vinho & Lanceolado & VE & Média & Não \\
\hline 15 & 497,00 & 110,25 & 99,92 & 30,33 & 95,17 & 1,76 & 13,79 & 16,88 & 309,73 & 243,95 & 12,13 & 10,04 & verde & Globoso & $\mathrm{RC}$ & Média & Não \\
\hline 16 & 530,67 & 113,50 & 120,58 & 28,58 & 143,25 & 1,46 & 13,79 & 17,75 & 300,35 & 189,95 & 8,96 & 8,25 & vinho & Globoso & RM & Média & Não \\
\hline 17 & 515,67 & 149,42 & 128,25 & 23,92 & 164,00 & 1,35 & 14,06 & 18,58 & 403,62 & 287,15 & 9,92 & 8,04 & vinho & Globoso & VM & Média & Não \\
\hline 18 & 503,08 & 115,00 & 105,25 & 25,50 & 146,50 & 1,48 & 13,00 & 14,96 & 357,40 & 245,47 & 8,38 & 7,33 & vinho & Lanceolado & VE & Média & Não \\
\hline 19 & 484,08 & 137,08 & 128,17 & 20,42 & 104,33 & 1,21 & 12,68 & 14,58 & 277,70 & 215,56 & 11,13 & 9,38 & verde & Lanceolado & $\mathrm{RC}$ & Pouca & Não \\
\hline 20 & 461,92 & 115,92 & 96,42 & 22,92 & 137,33 & 1,43 & 12,94 & 16,13 & 356,83 & 252,04 & 12,00 & 9,21 & verde & Lanceolado & $\mathrm{RC}$ & Média & Não \\
\hline
\end{tabular}




\begin{tabular}{|c|c|c|c|c|c|c|c|c|c|c|c|c|c|c|c|c|c|}
\hline 21 & 474,42 & 132,33 & 95,25 & 24,58 & 125,58 & 1,44 & 13,93 & 16,75 & 321,97 & 226,58 & 8,25 & 7,42 & vinho & Globoso & VE & Média & Não \\
\hline 22 & 34,67 & 127,58 & 148,42 & 29,83 & 127,58 & 1,44 & 12,96 & 15,28 & 341,36 & 270,44 & 12,79 & 11,58 & vinho & Lanceolado & $\mathrm{RC}$ & Média & Não \\
\hline 23 & 77,92 & 156,17 & 132,50 & 22,58 & 149,83 & 1,32 & 14,68 & 17,00 & 459,25 & 354,36 & 10,58 & 9,21 & vinho & Globoso & VM & Média & Não \\
\hline 24 & 37,08 & 133,17 & 134,25 & 27,58 & 152,75 & 1,47 & 15,26 & 19,29 & 397,43 & 294,83 & 11,25 & 9,50 & vinho & Globoso & $\mathrm{RC}$ & Muita & Não \\
\hline 25 & 572,42 & 150,33 & 127,42 & 28,17 & 150,17 & 1,51 & 14,21 & 18,25 & 452,94 & 312,79 & 9,25 & 7,96 & vinho & Globoso & RM & Média & Não \\
\hline 26 & 575,08 & 141,92 & 159,00 & 24,75 & 125,17 & 1,53 & 12,04 & 16,13 & 270,51 & 178,40 & 11,17 & 8,83 & vinho & Lanceolado & VE & Pouca & Não \\
\hline 27 & 479,75 & 142,67 & 151,83 & 27,50 & 129,50 & 1,21 & 13,58 & 17,00 & 294,09 & 229,13 & 9,42 & 8,08 & vinho & Lanceolado & RM & Média & Não \\
\hline 28 & 501,17 & 135,67 & 144,00 & 25,00 & 147,58 & 1,09 & 12,88 & 17,79 & 401,25 & 263,12 & 10,25 & 8,96 & vinho & Lanceolado & RM & Média & Não \\
\hline 29 & 491,33 & 134,75 & 148,75 & 27,08 & 108,67 & 1,16 & 14,17 & 17,71 & 362,68 & 280,60 & 10,00 & 8,54 & verde & Globoso & VM & Média & Não \\
\hline 30 & 554,33 & 121,50 & 155,58 & 27,08 & 162,83 & 1,58 & 15,46 & 19,33 & 490,73 & 364,19 & 10,08 & 8,58 & vinho & Globoso & RM & Muita & Não \\
\hline 31 & 531,25 & 132,17 & 116,92 & 30,08 & 151,42 & 1,55 & 15,58 & 18,88 & 497,42 & 320,51 & 11,79 & 9,79 & vinho & Globoso & RM & Muita & Não \\
\hline 32 & 529,33 & 118,75 & 134,92 & 25,25 & 131,17 & 1,52 & 13,86 & 17,38 & 347,78 & 251,76 & 11,42 & 9,58 & vinho & Globoso & VM & Média & Não \\
\hline 33 & 513,08 & 135,92 & 148,17 & 26,83 & 135,58 & 1,38 & 12,38 & 14,92 & 371,70 & 269,45 & 10,54 & 8,88 & vinho & Lanceolado & RM & Pouca & Não \\
\hline 34 & 531,67 & 138,58 & 116,75 & 25,00 & 96,75 & 1,24 & 11,29 & 12,75 & 243,18 & 196,69 & 10,58 & 8,54 & vinho & Lanceolado & VM & Pouca & Não \\
\hline 35 & 581,50 & 138,67 & 140,83 & 27,83 & 168,08 & 1,81 & 12,88 & 15,25 & 495,06 & 326,17 & 10,83 & 9,21 & vinho & Lanceolado & VM & Média & Não \\
\hline 36 & 593,50 & 121,75 & 115,83 & 33,33 & 114,33 & 1,65 & 13,88 & 16,13 & 311,68 & 233,82 & 10,46 & 8,79 & verde & Globoso & VE & Média & Não \\
\hline 37 & 566,42 & 125,92 & 134,58 & 28,33 & 159,67 & 1,31 & 13,13 & 15,79 & 434,07 & 296,28 & 9,96 & 8,17 & vinho & Lanceolado & RM & Média & Não \\
\hline 38 & 564,50 & 153,92 & 147,00 & 25,92 & 93,50 & 1,32 & 14,54 & 18,13 & 343,48 & 298,48 & 10,50 & 8,79 & vinho & Globoso & $\mathrm{RC}$ & Média & Não \\
\hline 39 & 580,25 & 125,00 & 138,58 & 27,00 & 104,75 & 1,48 & 14,08 & 17,92 & 342,08 & 285,20 & 9,83 & 8,08 & vinho & Globoso & RM & Média & Não \\
\hline 40 & 31,67 & 96,25 & 116,25 & 22,58 & 113,25 & 1,79 & 15,86 & 20,33 & 427,47 & 337,22 & 11,46 & 9,00 & vinho & Globoso & VM & Muita & Não \\
\hline 41 & 458,50 & 136,17 & 121,67 & 27,58 & 123,42 & 1,33 & 13,79 & 16,92 & 346,02 & 256,75 & 8,75 & 7,71 & vinho & Globoso & VE & Média & Não \\
\hline 42 & 503,33 & 119,42 & 129,92 & 26,33 & 103,83 & 1,54 & 14,29 & 18,04 & 341,01 & 284,88 & 10,38 & 8,25 & vinho & Globoso & RM & Média & Não \\
\hline 43 & 525,50 & 125,92 & 102,33 & 24,75 & 134,92 & 1,80 & 15,83 & 20,21 & 441,22 & 341,15 & 10,42 & 8,71 & vinho & Globoso & VE & Muita & Não \\
\hline 44 & 555,67 & 138,33 & 134,42 & 27,58 & 164,08 & 1,73 & 16,50 & 21,04 & 548,08 & 374,19 & 10,00 & 8,71 & vinho & Globoso & RM & Muita & Não \\
\hline 45 & 471,25 & 130,00 & 134,42 & 27,17 & 164,67 & 1,34 & 13,63 & 16,96 & 456,15 & 311,59 & 10,75 & 8,21 & verde & anceolado & VM & Média & Não \\
\hline 46 & 480,17 & 138,75 & 128,08 & 24,83 & 137,50 & 1,37 & 15,21 & 17,67 & 388,53 & 286,09 & 12,58 & 9,13 & verde & Globoso & VM & Muita & Não \\
\hline 47 & 489,58 & 121,67 & 107,58 & 22,50 & 141,33 & 1,44 & 12,92 & 14,67 & 355,30 & 239,59 & 10,04 & 8,46 & verde & Lanceolado & RM & Média & Não \\
\hline 48 & 499,83 & 120,00 & 133,08 & 23,75 & 111,58 & 1,42 & 13,38 & 16,17 & 302,54 & 237,76 & 10,54 & 8,67 & verde & Lanceolado & VM & Média & Não \\
\hline 49 & 574,83 & 112,08 & 137,08 & 28,50 & 138,17 & 1,49 & 13,08 & 15,88 & 375,03 & 281,91 & 10,75 & 8,88 & verde & Lanceolado & VE & Média & Não \\
\hline 50 & 71,33 & 126,00 & 113,58 & 30,33 & 153,00 & 1,53 & 14,97 & 17,92 & 493,15 & 306,96 & 12,75 & 9,71 & vinho & Globoso & RM & Muita & Não \\
\hline 51 & 446,25 & 131,00 & 112,17 & 25,00 & 94,50 & 1,55 & 13,91 & 17,38 & 342,21 & 284,23 & 9,63 & 8,00 & vinho & Globoso & RM & Média & Não \\
\hline 52 & 19,08 & 113,92 & 127,33 & 27,92 & 7,50 & 1,41 & 13,42 & 16,71 & 325,49 & 280,28 & 12,75 & 10,54 & vinho & anceolado & VE & Média & Não \\
\hline 53 & 463,75 & 120,00 & 132,17 & 29,58 & 103,08 & 1,30 & 12,75 & 14,08 & 262,45 & 194,87 & 10,63 & 9,04 & vinho & Lanceolado & VM & Média & Não \\
\hline 54 & 470,67 & 129,67 & 136,00 & 27,58 & 113,50 & 1,38 & 14,59 & 17,29 & 343,26 & 254,34 & 10,88 & 9,13 & verde & Globoso & VM & Média & Não \\
\hline 55 & 510,67 & 123,17 & 115,00 & 28,17 & 124,25 & 1,25 & 12,13 & 14,17 & 325,71 & 249,03 & 11,96 & 9,75 & vinho & Lanceolado & VM & Pouca & Não \\
\hline 56 & 77,92 & 136,67 & 98,17 & 29,67 & 87,00 & 1,39 & 13,13 & 15,92 & 277,40 & 226,09 & 11,29 & 9,88 & verde & Lanceolado & $\mathrm{RC}$ & Média & Não \\
\hline 57 & 44,25 & 119,83 & 97,92 & 28,42 & 121,67 & ה & 13,54 & 16,66 & 323,05 & 255,68 & 11,79 & 10,00 & vinho & Lanceolado & VM & Média & Não \\
\hline 58 & 47,33 & 115,50 & 84,33 & 28,08 & 114,58 & 1,26 & 12,79 & 14,46 & 271,00 & 204,20 & 11,46 & 8,71 & vinho & lado & $\mathrm{RC}$ & Média & Não \\
\hline 59 & 414,58 & 121,58 & 82,17 & 27,58 & 96,67 & 1,18 & 10,58 & 12,58 & 239,23 & 187,91 & 8,71 & 7,54 & verde & Lanceolado & $\mathrm{RC}$ & Média & Não \\
\hline 60 & 36,08 & 114,92 & 114,08 & 28,58 & 121,92 & 1,37 & 12,67 & 14,88 & 288,73 & 205,92 & 9,17 & 8,25 & verde & & RM & Média & Não \\
\hline 61 & 460,17 & 105,33 & 79,33 & 25,58 & 135,17 & 1,59 & 13,33 & 17,42 & 329,05 & 253,21 & 10,71 & 8,75 & verde & Lanceolado & VM & Média & Não \\
\hline 62 & 469,25 & 125,58 & , & 27,08 & 119,25 & 1,33 & 11,71 & 14,08 & 265,56 & 200,27 & 10,29 & 8,88 & verde & Lanceolado & VE & Pouca & Não \\
\hline 63 & 464,08 & 133,58 & 112,50 & 27,42 & 100,58 & 1,52 & 13,79 & 18,00 & 358,20 & 282,86 & 11,88 & 9,96 & verde & Globoso & VE & Média & Não \\
\hline 64 & 12,83 & 127,92 & 98,75 & 28,58 & 112,75 & 1,73 & 15,00 & 19,42 & 401,11 & 324,76 & 11,54 & 10,38 & verde & Globoso & $\mathrm{RC}$ & Muita & Não \\
\hline 65 & 167 & 5,58 & & 5,33 & 3,25 & 1,48 & 12,83 & 15,17 & 70,73 & 83,68 & 11,17 & 9,71 & erde & lado & VE & Média & Não \\
\hline
\end{tabular}




\begin{tabular}{|c|c|c|c|c|c|c|c|c|c|c|c|c|c|c|c|c|c|}
\hline 66 & 640,75 & 149,50 & 111,00 & 33,42 & 149,33 & 1,75 & 14,63 & 19,79 & 532,48 & 430,35 & 20,46 & 14,21 & vinho & Globoso & RM & Média & Não \\
\hline 67 & 449,25 & 122,67 & 135,08 & 29,50 & 158,42 & 1,88 & 14,48 & 19,79 & 519,31 & 333,66 & 15,79 & 12,00 & vinho & Globoso & RM & Média & Não \\
\hline 68 & 408,17 & 120,17 & 96,92 & 22,58 & 94,50 & 1,52 & 12,13 & 16,25 & 303,27 & 278,31 & 7,83 & 7,13 & verde & Lanceolado & RM & Pouca & Não \\
\hline 69 & 481,58 & 121,83 & 101,17 & 28,42 & 107,25 & 1,31 & 12,04 & 17,63 & 350,33 & 287,35 & 9,33 & 7,71 & vinho & Lanceolado & VE & Pouca & Não \\
\hline 70 & 427,92 & 112,58 & 100,58 & 24,83 & 112,08 & 1,22 & 12,42 & 17,17 & 252,93 & 187,91 & 10,29 & 8,67 & verde & Lanceolado & VM & Pouca & Não \\
\hline 71 & 464,83 & 111,17 & 114,42 & 25,25 & 116,50 & 1,28 & 12,88 & 17,88 & 293,39 & 242,61 & 7,29 & 7,04 & verde & Lanceolado & VE & Média & Não \\
\hline 72 & 484,83 & 119,33 & 93,92 & 26,42 & 117,33 & 1,28 & 13,08 & 16,04 & 303,63 & 230,41 & 10,38 & 8,58 & verde & Lanceolado & VM & Média & Não \\
\hline 73 & 413,58 & 116,08 & 109,42 & 23,17 & 135,08 & 1,58 & 14,91 & 19,52 & 430,36 & 321,66 & 9,00 & 7,96 & verde & Globoso & VM & Muita & Não \\
\hline 74 & 560,25 & 137,25 & 116,00 & 29,08 & 138,67 & 1,53 & 13,75 & 17,33 & 372,67 & 263,88 & 10,21 & 8,71 & verde & Globoso & $\mathrm{RC}$ & Média & Não \\
\hline 75 & 466,33 & 124,08 & 107,50 & 19,08 & 116,00 & 1,43 & 13,63 & 18,38 & 431,67 & 332,72 & 10,46 & 8,92 & verde & Lanceolado & RM & Média & Não \\
\hline
\end{tabular}

CFO: comprimento foliar; LLF: Largura foliar; CPF: comprimento do pecíolo foliar; NFO: número de folíolos; CHF: comprimento da haste floral; DHF: diâmetro da haste floral; AIN: altura da inflorescência; DIN: diâmetro da inflorescência; MFI: massa fresca total da inflorescência; MFC massa fresca comercial da inflorescência; DLI: diâmetro longitudinal da infrutescência; DTI: diâmetro transversal da infrutescência; COH: cor da haste floral; FIN: formato da inflorescência; COB: cor da bráctea da inflorescência brácteas (VE: vermelho escuro; VM: vermelho médio; RC: rosa claro; RM: rosa médio); PMI: projeção do miolo da inflorescência; PFB: presença de folha na bráctea. 